\section{The Flip-Flop Trail and Fragile Globalization}

\section{Caroline Knowles}

Goldsmiths, University of London
Theory, Culture \& Society $0(0) 1-14$

(C) The Author(s) 2015 Reprints and permissions: sagepub.co.uk/journalsPermissions.nav DOI: $10.1|77 / 02632764| 5576217$

tcs.sagepub.com

(SSAGE

\begin{abstract}
The flip-flop trail is an object biography. It follows the translocal journeys of a pair of plastic sandals, unpacking the lives and landscapes hidden in the plastic. An important shoe-infrastructure enabling human mobility, flip-flops work as an offbeat proxy for globalization too. They proffer empirical footings in translocally-connected worlds in which people and the social textures and terrains of their everyday lives come to the fore, in place of economic processes and commodity chains favoured in hegemonic versions of globalization. These reduce globalization's complex social forms to the grand narratives of the logics of capital accumulation, implicitly naturalizing it, if critically, as inevitable, entrenched and robust. From the vantage point of the flipflop trail, globalization looks rather different. It is more fragile and shifting, generating multiple forms of uncertainty in the lives and landscapes it simultaneously sustains and undermines.
\end{abstract}

\title{
Keywords
}

Fragile, globalisation, landscapes, lives, mobility

\section{Introduction}

The flip-flop trail is an object biography (Kopytoff, 1986) which follows a pair of plastic sandals. As the world's cheapest and most popular shoe, flip-flop sales rise with world population. A billion people walk barefoot (Tenner, 2005) and flip-flops are a first step into the world of shoes. An important shoe-infrastructure enabling human mobility, flip-flops work as an offbeat proxy for globalization too. They proffer empirical footings in translocally-connected worlds in which people and the social textures and terrains of their everyday lives come to the fore, in place of economic processes and commodity chains favoured in hegemonic versions of globalization (Held et al., 2003: 3; Sassen, 1998, 2007; Giddens, 2002; Castells, 1999, 2001, 2010). These reduce globalization's complex social forms to the grand narratives of the logics of capital accumulation (Smith, 2001: 23; Abu-Lughod, 2007), implicitly naturalizing it, if 
critically, as inevitable, entrenched and robust. From the vantage point of the flip-flop trail, globalization looks rather different. It is more fragile and shifting, generating multiple forms of uncertainty in the lives and landscapes it simultaneously sustains and undermines.

The trail is mapped conceptually through the following literatures. As varied co-productions of space, social and human fabrics (Lefebvre, 2000; de Certeau, 1988; Massey, 2005; Hannerz, 2010; Amit and Mitchell, 2010); as entanglements of social lives and objects (Appadurai, 1986; Miller, 2005, 2008) and the materials from which objects are made (Bennett, 2010): in the fabrications of the late 20th and early 21st centuries, plastics predominate. The trail expands and humanizes supply chain geographies (Gereffi and Korzeniewicz, 1994; Rothenberg-Aalami, 2004; Hughes and Reimer, 2004; Ciccantell and Smith, 2009; Reynolds, 2002) and develops the insights of other object trails (MacGaffey and Bazenguissa-Ganga, 2000; Barndt, 2008; Marriott and Minio-Paluello, 2012; Tsing, 2005). Critically extending (Knowles, 2010) the mobility paradigm's ideas of flow (Urry, 2010 [2000]), the trail draws on conceptions of walking as mobile spatial productions of daily life (Ingold, 2000; Benjamin, 2002; Shehadeh, 2007; de Certeau, 1988; Massey, 1999, 2005) I call journeys (Knowles and Harper, 2009; Knowles, 2014). These are temporally defined episodic and continuous sequences of movement which ground specifics - who, what, where, how and why - revealing social worlds from inside the logics of travel.

\section{Oil}

The flip-flop trail begins in Kuwait. A major oil producer and part of a significant oil-producing region in the Middle East, Kuwait exports 87 per cent of its oil and favours Asia's growing (plastic producing) markets. Plastics, of course, are made from hydrocarbons. Here, in this tiny kingdom, the social textures of the trail are made accessible through my ethnographic engagement with the routine daily and life journeys the spatial biography - of an oil geologist. The architecture of his life, composed in prayer at the mosque; his work for the government-owned Kuwait Oil Company, 'reading the rocks' to establish the oil reserves beneath the desert; and his social obligations to family and friends generate the journeys he navigates. At the same time they reveal the oil landscape through which he travels. This consists in the large campuses at the Al Hammadi oil headquarters, from where oil is exported; its company housing, stratified by rank; holding tanks, pipelines, oilrigs and the desert settlements of migrant oil workers around them, as well as the detritus which oil generates.

Oil literally makes Kuwait and the lives of its citizens; it makes its impressive GDP; accounts for 95 per cent of its export earnings and 
for 95 per cent of the government revenues (Rifkin, 2002) on which its citizens depend for their jobs, their high living standards and the leisure time it affords. Foreign migrants, many of them oil workers rotating in and out of Kuwait on 26 and 48 day work-cycles from other parts of the Middle East and South India, make up 60 per cent of Kuwait's workforce (2012; see www.cia.giv/library/publications/the-world-factbook/ geos $/ \mathrm{ku} . \mathrm{html})$. Kuwaitis are a $(45 \%)$ minority in their own country.

The trail through Kuwait - unlike much of the rest of the trail - is not one of globalization's backroads. Oil is as mainstream, as hegemonic, as central to globalization as any substance can be. Oil literally constitutes globalization. It makes it possible. Oil provides the energy to transport people and objects worldwide. Oil is responsible for the very time-space compressions that constitute globalization. The early 21 st century is still an oil and road economy: oil is globalization's central material substance and supports a key vector of translocal connectivity. Geopolitics is shaped by the scramble to secure and distribute oil around a shifting matrix of markets/regimes. The geographies of pipelines and tankers draw the contours of the world in which we live. Sanctions against Iranian oil administered a form of punishment that led to changes in Iran's government; Russian oil reinstates Cold War politics in new forms; the United States released itself from reliance on Middle Eastern oil with shale gas and Canadian tar sands. Al Hammadi lies at the centre of a giant transnational web of circulating workers, contractors, expertise and technologies, linking it with other oil cities like Calgary, Aberdeen, Stavanger and Houston, as well as cities across Saudi Arabia and other parts of the Middle East.

While securing stable oil supplies is problematic for those countries without it, societies shaped by oil production have their own problems. Inside the security of Kuwaiti oil prosperity multiple insecurities are revealed in the public and private conversations of Kuwaitis. What happens when the oil runs out? Where is the sovereign wealth fund and how much is in it? How is it administered? What will happen as a result of the growing militancy in Gulf states, also the location of the world's largest remaining oil deposits, as local sources of uncertainty are distributed globally along the oil pipelines? Kuwaiti oil is state owned and controlled, but can the governing class be trusted to act beyond their own interests? Political and economic calculations on a global scale prioritize oil and connect it with theatres of war. The destruction of Kuwaiti oilfields, ignited by retreating Iraqi forces in the 1990 invasion of Kuwait, generated a grammar of images that have become part of the iconography of war. Kuwait City still bears, 20 years later, the scars of the first Gulf war in its ruins - in the main market and at the National Museum, still to be rebuilt; these scars on the urban landscape reverberate the uncertainties voiced in Kuwaiti conversations. Mainstream globalization, it seems, sustains multiple uncertainties and fragilities. 


\section{Petrochemicals}

As the oil tanker from Kuwait approaches the coast of South Korea at Daesan, corporate Korea rises to meet it. The jetties of the giant corporations - Hyundai Oil Bank, Samsung Total, LG and the Lotte Daesan Petrochemical Corporation - key players in mainstream globalization, pump the oil into a landscape that is covered with oil refineries and petrochemical plants. These are sequestered in the countryside and can only be seen at a distance through security fences and razor wire. Once ashore, the oil is routed through cracking plants where it is dissembled into the constituents petrochemical plants require, the chemical building blocks from which the fabrics of everyday life - soap, detergent, solvents, paints, drugs, fertilizers, pesticides, explosives, synthetic fibres and rubbers, flooring, insulation and plastics - are manufactured. The flipflop trail is routed through the polymer - polyethylene (PE) - section of the plant as these particular plastics, along with EVA, make flip-flops.

Here it meets one of the polymer production teams specializing in PE. The team works together, often socializes together and lives in the company apartments close to the plant. Theirs are collective journeys, everyday lives lived in step; I have explored and narrated this as a group biography. Their stories reveal how corporate Korea supplies the fabric of everyday life, in a tightly hierarchized structure of employment, high pay, transport, housing and leisure facilities: short, repetitive, journeys, compose the fabrics of a comfortable daily life for core workers in key corporations such as these.

These circumstances scale-up to reveal broader social conditions countrywide. High wages are part of a GDP per capita of over US\$24,000 in 2012 (The Economist, 21 November 2012). South Korea today is a wealthy, highly educated and advanced country with a well-developed service sector. This service sector offsets some of the insecurities of South Korea's reliance on oil supplies for its petrochemical industries, its traditional engine of growth and prosperity. South Korea has no oil and no pipeline. Yet it is the ninth largest consumer of oil in the world. Half of its imported oil is fed into the petrochemical industry and it has three of the world's ten largest refineries (US Energy Information Administration, 2012). The petrochemical industry cannot exist without oil; a disruption in supply would decimate it. Large oil price rises would erode its profitability. As with oil, a source of strength is also a source of instability and fragility, even within the apparently robust framework of mainstream globalization. The same insecurities shape the personal lives of Korean citizens.

Korean lives are delicately balanced around the fragilities that come with being a major purchaser and processor of oil. Excellent employment conditions and pay in major industries, run by key corporations, come at the expense of poorer conditions in other industries, and subcontracted work inside major companies. The salaries of core petrochemical workers 
come at a cost borne by other workers. The biggest social divisions are between those in regular and those in irregular (informal) work, and between those in full-time and those (mainly women) in part-time work. An elite, highly paid, workforce with stable conditions of employment in core industries, coupled with substantial benefits, means casualization and subcontracting for others, producing wide social disparities. In the mid-2000s 14.6 per cent of the Korean population lived in relative poverty, defined as less than 50 per cent of median income. Forty per cent of Korean employees do not have regular employment. The youth unemployment rate is over 8 per cent (in 2010) and there is minimal social welfare provision (BTI, 2012): Koreans dig clams, run cafes and drive taxis in their old age to make ends meet.

The raw materials from which the plastic fabrics of everyday life are composed move on from Daesan in all directions. A major junction between what I have been calling mainstream globalization and backroad globalization is formed at this point. Distinctions between globalizations are descriptive rather than analytic; in fact the two are closely interconnected. The main business of petrochemical companies is routed along profitable main roads - many of them leading to China - which focus on high-end, high-value materials, like synthetic rubbers that make car bumpers, door seals and so on. Alongside these mainstream routes minor (backroad) trails are forged. Among them travel low-value plastic pellets used to manufacture cheaper objects, like flip-flops, from polyethylene and EVA. What happens at these junctions, how trails splinter, provides fertile analytic opportunities to rethink globalization from the vantage point of specific forms of traction, and the objects, materials and people travelling through crucial points. What rerouting opportunities present themselves at these junctions? And could these opportunities route better resources through backroads?

\section{Manufacture}

Chinese flip-flop manufacture is the story of China writ small. A large proportion of the world's flip-flops, uncounted billions of them, are made here using plastic pellets imported from Korea, in small to medium sized factories in industrial villages on the southern outskirts of Fuzhou. Factories emerged in the 1990s following the Deng Xiaoping reforms, which produced the Special Economic Zones designed to attract foreign investment, technologies and growth. China doubles its output and its personal incomes every 10 years (Ramo, 2004: 20). It is the world's second biggest economy. Flip-flop manufacture lives alongside this world on the same zeitgeist, the same idea that things can be made as a way of making a life.

Factory workers make flip-flops as they manufacture their own lives. Their production is embedded in, and expressed through, routine local 
journeys - from home to the factory - and in the minute choreographies of production and journeys around the village. The world's simplest and cheapest shoe is made through ten different production processes: weighing and mixing ingredients, rolling, weighing and assembling the plastic sheets to the correct thickness, vulcanizing (melding multiple plastic sheets into one), stamping out or mould-pressing the soles, trimming them, attaching straps, bundling and packaging into sacks, shifting the sacks to the yard for trucking, and clearing up scrap. It takes a minimum of 12 or, more usually, 16 to 20 people to produce a single pair of flipflops. Each of these processes has a set of routine technical skills attached to it and a biography - a factory worker's life story - enacted in multiple journeys of varied length. Close examination of factory workers' journeys reveals longer ones: journeys from the rural villages of the west to the factories in the east. Factory workers are rural migrants; they belong to the 100 million who have, since the late 1980 s, moved to "live beyond our planting, as one of them described it to me: the biggest peacetime movement of people in history (Murphy, 2002: 33). Their journeys connect industrial with distant rural landscapes along circuits that are about food and family, with elders and children remaining in the countryside.

The routine daily journeys of rural migrants around the industrial villages where flip-flops are made reveal the impact of plastic manufacture on the landscape. Plastics shape the architectures of these industrial villages, marking social distinctions in humble two-roomed dwellings for workers and grander houses for those who make multiples of factory wages. They fabricate the population densities and social distinctions in the villages between rural migrants and locals, who once farmed and now rent out their houses to migrants. Developers and industrialists have first call on land that was once farmed, and which now buzzes with the motilities of 24-hour factory production. Large hills of brightly coloured plastic, scrap from flip-flop production, are dotted around the landscape between its densely packed factories; bits of blue plastic carrier bags clog ditches, and plastic objects like buckets and bowls fill the village stores. These villages are fabricated in plastic and by plastic.

Plastic's lives are lived precariously on the landscapes of this particular global backroad. Flip-flop production demands flexibility: workers migrate between factories in efforts to secure work. In the 2008 recession, many returned to their farms in the west to wait for better times. Flip-flop production involves easily learned technical skills and low start-up costs, making them a starter-kit for those with an inclination towards making things, as a way of making money and improving social circumstances. Factory fortunes were made from humble flip-flop beginnings: from installing a mixer in the family home and deploying family labour. Flip-flops are all about possibility and becoming. They capture the Chinese dream of improving circumstances. But ease of access to production is also a source of instability. Flip-flop production is highly 
mobile. It migrated to China when Taiwan - and, earlier, Japan - moved up the value chain. It is now in the process of migrating to Vietnam, to Sudan, to Egypt, to Ethiopia and other parts of the African continent. Improvements in working conditions and wages in China will drive this low-value object into other lives and into other locations. Particular forms of uncertainty are part of its production: it provides cheap shoes and low wages for the poor and small profit margins for factory bosses.

As flip-flops leave the factories, loaders lift them into containers, and truck drivers take them to the port in Fuzhou. Here crane operators load them onto feeder ships, which meet up with mother ships at the Singapore hub for the long sea journey east. At the nearest hub port they are reloaded once more onto a feeder ship for the trip to Djibouti. Truck drivers, sailors and dockworkers, whose lives we know little about, propel them on their way. Across Somali landscapes flip-flops travel to Ethiopia - on account of its large population ( 84 million) and low GDP one of the biggest markets for Chinese flip-flops - through one of two intertwined transportation and logistics systems. These are, loosely, 'official' and 'unofficial' systems of travel and arrival, which are in practice entwined. The official route lands at the port of Djibouti, crosses the Ethiopian border paying import duties near Dire Dawa, and moves along the main road by truck to Addis Ababa. Unofficial routes involve landing points along the Somaliland coast, passing through the markets in the Somaliland city of Hargeisa and crossing the Ethiopian border along its less guarded sections, without paying import duties - ending up on the same markets in Addis as its official counterpart.

\section{Use and Disposal}

The flip-flop trail offers three routes through Addis Ababa, each with its own vantage point onto the city; the trail is also a way of dissecting cities for closer examination. The first are the series of trails through a matrix of markets, beginning with the wholesale/retail functions of the Mercato, perhaps the biggest outdoor market on the continent. This is connected with markets all over Ethiopia as well as with smaller markets around Addis and, ultimately, small kiosks on street corners all over the city. The second route follows from this: it is the city as known by the feet of an elderly woman who owns only one other pair of shoes as well as the flip-flops she bought from her local kiosk. Following her on the routine journeys of her daily life unfolds the city from the vantage point of her living it. We see her travelling to the local church, to the market to buy the potatoes, tomatoes and onions she sells from a square of cloth outside of her home in the poor inner city neighbourhood of Tekelehainmanot, and to her neighbour's houses for occasional 'coffee ceremonies' in which she practises reciprocity and catches up on the talk 
of the neighbourhood. She navigates these journeys in a pair of flip-flops repaired with a nail. Her four children are casually employed and two of them still live with her in her tiny three-room dwelling. Her husband is deceased. Talking with her neighbours reveals that her circumstances reflect those of others, and mirror broader ones, across the city and across the country.

In Addis, with its population estimated at three and a half million, commercial activities - largely informal and humble ways of getting by compose the fabric of everyday life, providing subsistence, in the absence of formal employment, for those who must survive on their own skill, on the opportunities which arise, and on the resources available. 'Desperate manoeuvres', 'endless circulation' and 'precariousness' describe the situation of urban Africans, who none the less manage to make lives in their cities and make cities in the process, as platforms onto the world beyond (Simone, 2002). All land is owned by the government and leased, only slowly developing an enterprise culture in the aftermath of the Marxist Derg, who governed Ethiopia between 1974 and 1990. But the private sector is still weak and the government operates monopolies. This reverberates through Ethiopian lives. The unofficial youth unemployment rate is estimated at 70 per cent (Egziabher, 2006). A generation of Ethiopian youth lacks opportunity and food security, and this remains a challenge for the authorities. Eighty per cent of Ethiopians live on less than US\$2 a day (The Economist, 2007) while managing basic multidimensional uncertainties.

Ethiopia is not simply described as one of globalization's backroads; significant main road global traffic passes through it too. A poster child for African development on account of its social programmes and efforts at democracy (until the 2005 elections marred by mass killing in Addis Ababa), it is a major recipient of US and UK foreign aid. And, connectedly, because of suspected jihadist operations staged by its Somali neighbours, and because it is known to have collaborated in the CIA programmes of extraordinary rendition (Autoreply@economist.com 1-11-07), Ethiopia is on the front line in the 'war on terror'. Thus it has high geopolitical significance in addition to being a major customer of cheap plastic goods manufactured in China.

The third route through Addis consists in the journeys made by the old woman's flip-flops once she disposes of them and they become a part of the city's efforts at rubbish disposal. This throws a particular spotlight on the city. Like many cities in the Global South, Addis struggles to collect its rubbish. The old woman's flip-flops are thrown in a skip and collected by the municipality which transports them to the giant landfill site, Koshe, on the city's southern edge. Koshe means dirty in Amharic. This, it seems, is the end of the trail: with no resale or recycling value, flip-flops will sit in the landfill for a hundred years. 
Working here on the rubbish dump, I discovered that the end of this particular trail is also the beginning of some new trails. Two to three hundred 'scratchers' - as they call themselves - live around (and sometimes on) the dump, salvaging materials that can be sold to recycling factories and food disposed of by airlines and hotels. Some are saving to fulfil their plans: one young woman told me she was accumulating the money to buy a visa and airline ticket so that she could become a maid in Dubai. This will inaugurate new routes, at least for her, from the end of the flip-flop trail. There are other trails too. The municipal authorities have plans to turn this vast site into a station that will generate biomass electricity, so discarded flip-flops may soon be turned into new forms of matter with new uses.

\section{Revisiting Globalization}

The flip-flop trail offers new empirical vantage points and geographies to existing work on globalization. Its backroads carry significant traffic. They reveal important streams of global migration and the rhythms, scales of movement and volition driving them. These backroads expose the logics of rural to urban migrations and differences in this regard between points on the trail. They expose female transnational migration between the Middle East and Ethiopia and migration of male oil workers between Kuwait and southern India and parts of the Middle East. They expose the traffic between Africa and China, which brings Chinese migrants to Africa, and African migrants to China. These backroads reveal what is happening in China, unpacking China's small-scale factory production and the lives it weaves. They reveal China's (quasicolonial?) relationship with Africa. Backroads are not backroads because they are insignificant; they are backroads only in being overlooked in hegemonic accounts of globalization. Backroad and main road globalization intersect, as I have shown, providing new analytic spaces from which to review and, possibly, reroute globalization.

The flip-flop trail reveals little-considered lives: a Kuwaiti oil geologist, a team of Korean petrochemical workers, several Chinese flip-flop production workers, the rise of the factory bosses, a Chinese interlocutor in accessing global markets, Ethiopian traders, smugglers, an elderly Ethiopian woman and three rubbish scratchers. The journeys composing these lives reveal striking similarities between Ethiopians and Chinese in the hyper-local geographies of their journeys, in the purposes relating to them, and in the skills with which they navigate them. Journeys place everyone in the same frame. They enable comparisons between locations, and between lives in the same locations. Journeys display the contours of comparative (dis)advantages. They offer a means of grouping and differentiating people which is more nuanced than social categories like class and gender, providing instead fine-grained portraits of lives and the 
circumstances of their living. Journeys reveal the scale on which lives are lived. They expose the hyper-local and the long distance traveller along with the rhythms of their routes. They reveal people's calculations and navigational skills, the capacities and circumstances that make their journeys possible.

The flip-flop trail reveals places too, combining biography with geography to provide the missing urban geographies of globalization. It offers a series of lenses through which cities can be apprehended and analysed, as I showed above in respect of Addis Ababa. It problematizes relationships between cities, as well as between cities and the routes composing them. Globalization is increasingly lived in and through cities. Journeys provide sophisticated urban analytics while placing the lives fabricating them at the centre of our concerns. This midrange concept - journey - brings vivid accounts of lives and landscapes to our conceptions of globalization, providing globalization's social fabrics and elaborating it from its narrow focus on business and economics.

Globalization has hitherto been viewed from a limited range of perspectives. Shifting the analytic angle creates a conceptual space for other versions of globalization, in other places, to take shape. The analytic angle opened by the flip-flop trail teaches us that globalization is more fragile than we think it is. It is more plural, more open and more motile than we hitherto understood it to be. It is constantly rerouted and opens new trails in new places. The constant emergence of new trails, new routes, new configurations and articulations of social and material fabrics forms the elusive and mutating substance of globalization. This unstable, shifting and ad hoc tangle of translocal routes, which reroute in directions that cannot be predicted, constitutes and reveals globalization's fragility: a fragility composed in its motility. Low wages and easily learned technical skills make flip-flop production possible in thousands of different locations, impossible to predict. An important flipflop interlocutor who takes orders globally and commissions production from a matrix of small Chinese factories without access to a global market on their own resources related to me his reverie of Middle Eastern feet in the sand, offering this as an explanation of the logic behind setting up a factory in Sudan. This branching of the trail could not be predicted from the logics of capital accumulation alone; it leans instead on imagination and eccentricity. The fragilities of life on the flipflop trail consist in such random motilities as well as systematic ones, like costs of production.

What is, perhaps, more surprising are the fragilities of globalization's hegemonic forms in oil and petrochemicals. Viewed from the humanistic perspective of the flip-flop trail, life in Kuwait and Korea is precarious in its own ways. On each of the platforms composing the trail, materials, objects and livelihoods can move in any number of directions. This is not 
to suggest that Kuwaiti, Korean, Chinese, Somali and Ethiopian fragilities are commensurable. They are clearly not. Fragilities take different forms and intensities in people's lives. They have different consequences and are framed by different structures of opportunity.

Globalization's fragilities and instabilities weave through and compose people's lives and journeys along the trail as incommensurable, personal, insecurities and precarities. Precarity refers to the different ways in which risk is shifted from public and commercial bodies onto the personal circumstances of individual workers and their families. This concept, developed to describe the severed bond between capitalism and the welfare state in the Global North, needs to be adapted for the purposes in hand. Precarity works as a description of conditions of existence in which ambient insecurity shapes the lives that can be lived, the journeys that can be undertaken. It describes human determination to survive adversity and it describes the possibilities offered by new, informal, spaces for social practice as people take matters into their own hands. Precarities manifest themselves in being unable to eat three times a day, circumstances which Chinese producers and Ethiopian consumers share. They are manifested in risking imprisonment for evading import duties on the Somali/ Ethiopian border; in having to drive a taxi or dig clams in old age in Korea; and in fearing invasion and violence in Kuwait. For much of the human substance of globalization we witness on the trail, the fragile and temporary forms of stability available in a shifting, precarious, world entail remaining poor, so that jobs are not relocated to still poorer places and even poorer people. People's navigational skills are attuned to the shifting precarities with which they co-exist. They are skilled navigators of globalization's precarities.

Globalization is anything but robust and stable. It is instead an inchoate, ad hoc matrix of shifting, cross-cutting trails that are difficult to anticipate, and even more difficult to live. Globalization produces fragile and precarious lives, even for those who live in its more privileged locations. Among the seething inchoate mobilities composing globalization, its hyper-locality is declared. Globalization is lived in houses and in neighbourhoods. It is lived through work. And it is lived in the social relationships of these restless groundings. What stretches these things beyond the local, what makes them global, is a chaotic patchwork of movement, on different scales, by different people, by objects like flip-flops, by materials like plastics. The flip-flop trail shows that globalization is made in little, hyper-local sections, all of them connected, in different ways, to the next stage or platform on the trail. At no point, and this would seem to be crucial in thinking about globalization, is an entire trail, or even large sections of it, revealed. Not even in the algorithms of logistics. Trails jolt uncertainly across the opaque intersections between neighbourhoods, locales and nation-states. 


\section{Conclusion}

The flip-flop trail discourages conceptual complacency, showing that globalization is always a work in progress. Only provisional assessments, pending further investigation of something so vast and diverse as globalization, are appropriate. Further investigation of a diverse range of circumstances and vantage points is urgently needed. In the interim our theoretical pronouncements should be provisional and the limitations of their circumstances acknowledged, moderating claims to general truths. Globalization is not what we think it is. As the flip-flop trail has shown, it is a loose patchwork of human and object journeys. It is an unstable, shifting, contingent mass of ad hoc-ery, with pockets of opportunity within overwhelming landscapes of precarity. Above all, globalization needs to be re-examined for the opportunities that manoeuvring its instabilities might provide for the mass of people worldwide who struggle in their own ways to navigate it. Unwinding globalization and taking a closer look at it provides a first step towards thinking about the political opportunities it embeds for opposing and rerouting the traffic that moves through lives and neighbourhoods. This in turn creates a platform from which new routes and journeys that are socially more just and less geared towards the deepening of poverty might be inaugurated.

\section{Acknowledgements}

This paper is drawn from a longer published work (see Knowles, 2014) and it has an accompanying website (www.flipfloptrail.com). I would like to express my deepest appreciation to the Leverhulm Trust, whose funding made this work possible.

\section{References}

Abu-Lughod J (2007) Globalization in search of a paradigm. In: Rossi I (ed.) Frontiers of Globalization Research: Theoretical and Methodological Approaches. New York: Springer, pp. 353-360.

Amit V and Mitchell J (2010) Series preface. In: Hannerz U (ed.) Anthropology's World. London: Pluto.

Appadurai A (ed.) (2005) The Social Life of Things: Commodities in Cultural Perspective. Cambridge: Cambridge University Press.

Barndt D (2008) Tangled Routes: Women, Work and Globalization on the Tomato Trail. Lanham: Rowman and Littlefield.

Benjamin W (2002) The Arcades Project. Cambridge, MA: Harvard University Press.

Bennett J (2010) Vibrant Matter: A Political Ecology of Things. Durham: Duke University Press.

BTI (2012) Bertelsmann Stiftung's Transformation Index: South Korea Country Report. Available at: www.bti-project.de/fileadmin/inhdte/reports/2012/pdf (accessed January 2014). 
Castells M (1999) Information Technology, Globalisation and Social Development. Geneva: UNRISD (UN Research Institute for Social Development).

Castells M (2001) Information technology and global capitalism. In: Hutton W and Giddens A (eds) On the Edge: Living with Global Capitalism. London: Vintage.

Castells M (2010) Preface. The Rise of the Network Society, 2nd edn. Oxford: Wiley Blackwell, pp. 15-16.

Ciccantell P and Smith DA (2009) Rethinking global commodity chains: Integrating extraction, transport and manufacturing. International Journal of Comparative Sociology 50(3-4): 361-384.

de Certeau M (1988) The Practice of Everyday Life. Los Angeles: University of California Press.

Egziabher TG (2006) The developmental impact of China and India on Ethiopia with emphasis on small scale footwear producers. Paper prepared for OECD in the framework of 'Development impact of the economic ascendancy of China and India on other developing countries'. Available at: http://www. tips.org.za/files/forum/2006/papers/TheDevelopmentalimpactofChinaandInd iaonEthiopia.pdf (accessed 12 March 2015).

Gereffi G and Korzeniewicz M (1994) Commodity Chains and Global Capitalism. Westport, CT: Greenwood.

Giddens A (2002) Runaway World. London: Profile Books.

Hannerz U (ed.) Anthropology's World. London: Pluto.

Held D, McGrew A, Goldblatt D and Perraton J (2003) Rethinking globalization. In: Held D and McGrew A (eds) The Global Transformations Reader. London: Polity.

Hughes A and Reimer S (eds) (2004) Geographies of Commodity Chains. London: Routledge.

Ingold T (2000) The Perception of the Environment. London: Routledge.

Knowles C (2010) Mobile sociology: Commentary on John Urry's work. British Journal of Sociology (Special Issue: Shaping Sociology Over 6o Years) 61(s1): 373-379.

Knowles C (2014) Flip-Flop: A Journey through Globalisation's Backroads. London: Pluto.

Knowles C and Harper D (2009) Hong Kong: Migrant Lives, Landscapes and Journeys. Chicago: University of Chicago Press.

Kopytoff I (1986) The cultural biography of things: Commoditization as process. In: Appaduri A (ed.) The Social Life of Things. Cambridge: Cambridge University Press, pp. 64-91.

Lefebvre H (2000) Writing on Cities. London: Blackwell.

Lemert C (2002) Dark Thoughts: Race and the Eclipse of Society. New York: Routledge.

Marriott J and Minio-Paluello M (2012) The Oil Road: Journeys from the Caspian Sea to the City of London. London: Verso.

MacGaffey J and Bazenguissa-Ganga R (2000) Congo-Paris: Transnational Traders on the Margins of the Law. Oxford: James Currey.

Massey D (1993) Politics and space/time. In: Keith M and Pile S (eds) Place and the Politics of Identity. London: Routledge, pp. 141-161. 
Massey D (1999) Imagining globalisation: Power geometries of time-space. In: Brah A, et al. Global Futures. London: Macmillan, pp. 27-44.

Massey D (2005) For Space. London: SAGE.

Miller D (2005) Materiality: An introduction. In: Miller D (ed.) Materiality. Durham: Duke University Press.

Miller D (2008) The Comfort of Things. London: Polity.

Murphy R (2002) How Migrant Labour is Changing Rural China. Cambridge: Cambridge University Press.

Ramo JC (2004) The Beijing Consensus. London: Foreign Policy Centre.

Reynolds LT (2002) Consumer/producer links in fair trade coffee networks. Sociologia Ruralis 42(4): 404-424.

Rifkin J (2002) The Hydrogen Economy. Oxford: Polity.

Rothenberg-Aalami J (2004) Coming full circle? Forging missing links along Nike's integrated production networks. Journal of Global Networks 4(4): 335-354.

Sassen S (1998) Globalization and its Discontents. New York: The New Press.

Sassen S (2007) A Sociology of Globalization. New York: W.W. Norton.

Shehadeh R (2007) Palestinian Walks: Notes on a Vanishing Landscape. London: Profile Books.

Simone M (2002) Opportunities, risks and problems in the urban sphere. Available at: www.africansocieties.org/eng_giugon2002/eng.citta 5/12/07 (accessed January 2014).

Smith MP (2001) Transnational Urbanism: Locating Globalisation. Oxford: Blackwell.

The Economist (2007) 'A Brittle Ally in the Horn of Africa' 1 November. Available at: http://www.economist.com/node/10062658 (accessed January 2014).

Tenner E (2003) Our Own Devices. New York: Knopf/Random House.

Tsing AL (2005) Friction: An Ethnography of Global Connection. Princeton: Princeton University Press.

Urry J (2010 [2000]) Mobile sociology. The British Journal of Sociology (Special Issue: Shaping Sociology Over 6o Years) 61(s1): 347-66.

US Energy Information Administration (2014) Analysis: Kuwait. Available at: http://www.eia.gov/countries/cab.cfm?fips=ku (accessed 12 March 2015).

World Factbook (2014) Kuwait. Available at: www.cia.giv/library/publications/ the-world-factbook/geos/ku.html (accessed 12 March 2015).

Caroline Knowles is co-director of the Centre for Urban and Community Research (CUCR) and Professor of Sociology at Goldsmiths, University of London. She is the author of Flip-Flop: A Journey Through Globalisation's Backroads, published by Pluto Press (2014) and accompanying website (www.flipfloptrail.com), co-author with Douglas Harper of Hong Kong: Migrant Lives, Landscapes and Journeys, published in 2009 by the University of Chicago Press as well as the author of numerous books and papers concerned with urbanism, race, ethnicity, globalization, trans-localities, mobilities and visual, biographical and ethnographic research methods. 